\title{
MAPEAMENTO DE DANOS EM MONUMENTO HISTÓRICO ART DÉCO
}

\author{
Damages mapping on Art Déco historical monument
}

\author{
Elianne Auxiliadora Moreira Borges ${ }^{1}$, Helena Carasek ${ }^{2}$, Oswaldo Cascudo ${ }^{3}$ \\ Recebido em 23 de março de 2014; recebido para revisão em 29 de abril de 2014; aceito em 22 de maio de 2014; \\ disponivel on-line em 11 de junho de 2014.
}

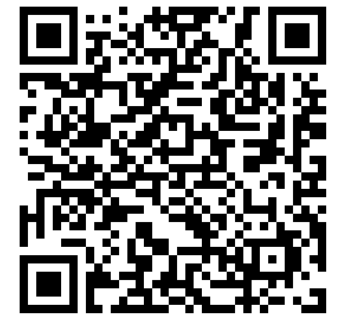

PALAVRAS CHAVE:

Revestimento;

Reboco lavado;

Reabilitação de fachadas;

Mapeamento de danos;

Patologias em edifícios.

\section{KEYWORDS:}

\section{Rendering;}

Washed Plaster;

Facades rehabilitation;

Damages mapping;

Buidings pathologies.

\begin{abstract}
RESUMO: Os revestimentos de fachadas exercem diversas funções nos edifícios e monumentos, entre as quais, funções estéticas, de durabilidade e de valorização econômica. Entretanto, com o passar dos anos, as obras começam a sofrer processos de deterioração, ora naturais ora provocados por ações de intervenção mal sucedidas, que desencadeiam o aparecimento de diversos problemas no revestimento, comprometendo essas funções. No caso dos edifícios e monumentos históricos, a situação é ainda pior, pois se somam a esses fatores, a falta de conhecimento dos materiais e das técnicas empregadas na execução deles na época da construção. Dessa forma, este artigo tem como objetivo apresentar um estudo de caso que consiste no procedimento utilizado para a inspeção e o mapeamento de manifestações patológicas dos revestimentos de um importante monumento art déco da capital goiana, a Torre do Relógio. $O$ estudo visou também levantar as causas e as possíveis remediações para as manifestações patológicas encontradas no revestimento estudado, que é do tipo reboco lavado. A expectativa final é dar contribuições aos trabalhos realizados em fachadas e voltados aos monumentos de valor histórico. Para o alcance desse objetivo, foi proposta a seguinte metodologia: (1) inspeção visual, para investigação e mapeamento das manifestações patológicas presentes no monumento; (2) documentação fotográfica; (3) ensaio por percussão, para avaliar o estado de aderência do revestimento e, ainda, (4) o ensaio de esclerometria de pêndulo, para avaliar a dureza superficial do revestimento. Como resultado, constatou-se que o monumento encontra-se deteriorado, com a presença de diversas anomalias no revestimento, principalmente, com elevado índice de fissuração e manchas de sujidade, além de manchas de oxidação e desagregação. As vistas Sul e a Norte são as que estão mais comprometidas enquanto que nas vistas Oeste e Leste, especialmente nesta última, o revestimento ainda continua em bom estado de conservação.

ABSTRACT: Facade rendering performs various functions in buildings and monuments including aesthetic features, durability and economic value. However, over the years, the constructions and monuments begin to suffer deterioration processes, either by a natural process or caused by unsuccessful intervention actions that trigger the onset of several problems in the building renderings, impairing their functions. In the case of historical buildings and monuments, the situation is even worse, because of the lack of knowledge of materials and techniques employed in implementing them at the time of construction. Thus, this article aims to present a case study held at the Clock Tower, an important art déco monument situated in the city of Goiânia, the capital of the Brazilian state of Goiás. The main objective of the work was to propose a procedure for inspection and mapping of pathological manifestations incident on renderings known as washed plaster. The study has also a contribution towards the discussion of the causes of the problems, as well as a contribution in terms of general corrective measures to the verified pathological manifestations. The final expectation is to contribute to the works on facades and monuments of historical value. To achieve this goal, it was proposed the following methodology: 1) visual inspection for assessment and mapping of pathological manifestations present at the monument; 2) photographic documentation; 3) percussion test to evaluate the state of rendering adhesion; and 4) a testing, by means of pendulum sclerometry, to evaluate the surface hardness of the rendering. As a result, it was found that the monument is deteriorated showing various defects in the rendering, such as a high cracking with dirt stains, rust stains and mortar disintegration. The south and north sides of the tower are those most committed while in the west and east views, especially in the latter, the rendering is still in good conditions.
\end{abstract}

\section{* Contato com o autor:}

${ }^{1}$ e-mail : auximor@yahoo.com.br ( E. A. M. Borges )

Mestranda do Prog. de Pós-Graduação em Geotecnia, Estruturas e Construção Civil - PPG-GECON da Univ. Federal de Goiás - UFG 2e-mail : hcarasek@gmail.com ( H. Karasek)

Prof. Dra., Programa de Pós-Graduação em Geotecnia, Estruturas e Construção Civil - PPG-GECON da Univ. Federal de Goiás - UFG 3e-mail : ocascudo@gmail.com (O. Cascudo)

Prof. Dr., Programa de Pós-Graduação em Geotecnia, Estruturas e Construção Civil - PPG-GECON da Univ. Federal de Goiás - UFG 


\section{INTRODUÇÃO}

Nos edifícios, normalmente os revestimentos de fachada são os primeiros elementos que necessitam de intervenções, devido à maior exposição às ações climáticas e de impacto mecânico e ambiental. As argamassas de revestimento devem comunicar intenções arquitetônicas e proteger a parede da ação direta dos agentes climáticos, de ações mecânicas de choques e erosão, da ação química da poluição e dos sais solúveis contidos nos materiais, na água e no solo. Além disso, devem contribuir para a estanqueidade à água e para o isolamento termo acústico, além de se constituir no acabamento final, exercendo funções estéticas, de durabilidade e de valorização econômica (VEIGA et al., 2004; RIBEIRO, 2006).

No caso dos edifícios antigos, Veiga et al. (2004, p. 15) destacam que "as argamassas antigas contam-nos a história tangível e intangível das gerações anteriores, garantindo autenticidade histórica, material e arquitetônica da apresentação dos imóveis ancestrais". Logo, o aspecto dos revestimentos de paredes condiciona significativamente o aspecto dos edifícios antigos e, consequentemente, dos bairros antigos.

Entretanto, apesar da importância dos revestimentos, em algumas regiões tem-se encontrado dificuldades nas ações de intervenção que poderiam amenizar a degradação desses elementos, sobretudo, pela falta de conhecimento dos materiais e das técnicas empregadas na execução dos edifícios antigos e de valor histórico. Especialmente em fachadas já restauradas, muitas manifestações patológicas, entre as quais, destacamento, desagregação, fissuração, manchas de umidade, surgem não necessariamente da ação direta exclusiva de agentes de deterioração ambientais, mas, sobretudo, decorrentes de intervenções mal sucedidas que, na maioria das vezes, são causadas pela incompatibilidade entre os materiais de reabilitação e os materiais a restaurar. $\mathrm{O}$ respeito à compatibilidade nas intervenções efetuadas em termos arquitetônicos, mecânicos e químicos, minimiza a alteração das características da rigidez da construção e do funcionamento estrutural original e, consequentemente, evita o aparecimento de situações de perda de desempenho e de novas manifestações patológicas (GUIMARÃES, 2009; TORGAL e JALALI, 2010). Por outro lado, os erros de projeto e de execução, as interações entre os fatores de degradação dos revestimentos e as demais partes da construção, entre outros, também podem desencadear 0 aparecimento de anomalias nos revestimentos.

Fica claro, portanto, que muitos são os fatores que intervêm e contribuem negativamente como agentes de deterioração em obras de valor histórico. Assim, buscar o conhecimento pleno desses fatores é fundamental. Nesse contexto, foram estudadas duas metodologias recentemente desenvolvidas para a inspeção em fachadas de valor histórico: a de Tinoco (2009) e a de Teles (2010). Na primeira, o autor desenvolveu um roteiro metodológico destinado a apresentar as maneiras técnicas mais apropriadas de documentação e representação do conhecimento, visando assegurar a qualidade nas investigações sobre as possíveis manifestações patológicas existentes em uma edificação de valor cultural. Para isso, recomenda a realização das Fichas de Identificação de Danos, que são os registros principais para a produção do Mapa de Danos, representação gráfico-fotográfica, sinóptica de todas as manifestações de deteriorações da edificação, ilustradas e discriminadas de forma rigorosa e minuciosa, sintetizando o resultado das investigações sobre as alterações estruturais e funcionais nos materiais, nas técnicas, nos sistemas e nos componentes construtivos, entre outros. Teles (2010), por sua vez, traz um trabalho que contribui para a conservação do patrimônio cultural arquitetônico, apresentando uma metodologia de levantamento de informações de danos, materiais e técnicas construtivas necessárias ao projeto de conservação de fachadas históricas revestidas em argamassa, especialmente, destinadas à etapa de levantamento quantitativo de danos.

Sobre o movimento art déco, Schelotto (1997) relata que ele foi uma expressão cultural complexa e diversa, que se desenvolveu de modo 
simultâneo em inúmeros planos e formas expressivas, com o objetivo exteriorizar um espírito moderno por meio da arte decorativa. Teve origem na Europa na década de 1920, sendo o auge durante as décadas de 1930 e 1940. Entretanto, o termo "art déco" só surgiu oficialmente em 1966, em Paris, após a exposição Les Années 25, realizada em comemoração à Exposition Internationale des Arts Décoratifs et Industrielles Modernes, de 1925, que também tinha sido realizada em Paris e de onde veio a origem do termo art déco (UNES, 2008). Diferentemente do Movimento Moderno, o art déco não pode ser definido como um movimento artístico, pois não dispunha de uma doutrina teórica unificadora, expressa por manifestos, associações ou publicações, que ordenasse a produção de acordo com conceitos definidos e consensuais, ou seja, era basicamente pragmático.

O estilo perdurou até meados da década de 1940, tendo se difundido rapidamente por vários países, tais como Estados Unidos, África do Sul, Austrália, Canadá, Portugal, Nova Zelândia, além de diversos países da América Latina como México, Cuba, Uruguai, Chile, Argentina e Brasil, entre outros. Após a Segunda Guerra Mundial se popularizou também em países como Coréia do Sul, Vietnã e China.

A difusão mundial do art déco foi bastante facilitada pelas adaptações que sofreu em cada país, fundindo-se em parte a movimentos nativistas e nacionalistas locais. Apesar disso, teve uma abrangência limitada, uma vez que conviveu com outras correntes artísticas, não chegando a alcançar a totalidade da produção de uma época ou região (CZAJKOWSKI, 2000; BORGES, 2006). Houve, por parte de alguns países da América Latina, a preocupação em recuperar a identidade nacional em detrimento aos modelos culturais centroeuropeus, principalmente, o francês, o alemão e o inglês. No Uruguai, por exemplo, o art déco é muito amplo e rico em sua diversidade de perfis e expressões. Apesar de possuir uma arquitetura muito conservadora até os anos 20, o estilo foi bem aceito em Montevidéu, não ficando restrito às edificações privadas ou domésticas, mas se estendendo aos cinemas, às garagens, aos postos de gasolina, às padarias, aos armazéns (DIAZ, 1997).

No Brasil, os principais acervos art déco são encontrados em São Paulo, Rio de Janeiro e Goiânia. Além dessas capitais, o estilo pode ser visto em Campo Grande, Belo Horizonte, Juiz de Fora (MG), Iraí (RS), Cipó (BA), Campina Grande (PB), entre outras. Obras como o Elevador Lacerda, em Salvador e a Torre do Relógio da Central do Brasil, no Rio de Janeiro, são dois exemplos clássicos dentre inúmeros outros construídos no país.

No contexto das edificações construídas no estilo art déco obteve-se a informação, por meio do relato de antigos mestres de obras, de que nas edificações brasileiras construídas a partir da década de 1930, sobretudo, nas capitais litorâneas, foi comum, além da tradicional pintura à base de cal ou óleo, o emprego de um revestimento constituído por cimento, mica e material pétreo, o qual poderia ser granito, mármore ou basalto. Devido a essa natureza pétrea, constituiu-se em um dos mais nobres e duradouros revestimentos, sendo estável a luz, podendo ser encontrado com variações de tonalidades, conforme o tipo e a quantidade de pedras empregadas (REZENDE, 2007 apud NASCIMENTO, 2008; LEVY e HELENE, 2010; CORREIA, 2008).

Durante a pesquisa, foram encontradas várias denominações para o tipo de revestimento usado nesse período, entre elas: argamassa de cimento penteado, argamassa de pó de pedra, revestimento em pó de pedra ou pó de pedreira, revestimento de mica, cirex, cirocreto, revestimento de pedra, reboco raspado, argamassa raspada, massa raspada, argamassa penteada, "reboco pintado", massa lavada e até mesmo marmorite, em Portugal, e que além disso, todos esses nomes encontrados na literatura, ora se referiam aos materiais ora se referiam ao processo executivo e, em alguns casos, a ambos. Diante do exposto, da necessidade de padronização da nomenclatura e a fim de facilitar o entendimento, será adotada ao longo desse estudo a denominação "reboco lavado" para caracterizar os revestimentos 
naturais utilizados em obras art déco, ressaltandose que embora bastante utilizado, esse revestimento não foi exclusivo nesse período tão pouco desse período.

Gonçalves et al. (2005), por exemplo, destacam que a técnica desse revestimento foi observada especialmente nos prédios construídos na década de 1950, de onde infere-se que a utilização da mesma não ocorreu no auge do período art déco, tendo sido observada também, conforme Junginger, Resende e Cordts (2006), em obras do século XVIII, como na Igreja Nossa Senhora da Consolação, em São Paulo, fundada em 1799 e reformada em 1840, cujo acabamento das fachadas é do tipo massa lavada.

Conceitualmente, o reboco lavado constituía-se em um tipo de revestimento aplicado sobre uma camada de regularização (emboço), cuja execução era feita usualmente em uma ou duas demãos, numa única camada, com espessura final variável entre 10 e $12 \mathrm{~mm}$, conhecida como massa fina. Tratava-se de uma argamassa de revestimento não pintada, em que o efeito decorativo era dado pelo agregado à vista, o qual era previamente selecionado quanto à cor, à dimensão e à forma, para conferir o aspecto pretendido. Posteriormente, a argamassa era apertada contra o substrato e no início do endurecimento era lavada, de modo a deixar à vista o agregado. 0 acabamento, por sua vez, era rústico devido ao sarrafeamento e à raspagem do reboco com ferramenta denteada (CASCUDO e CARASEK, 1992; LEVY e HELENE, 2010; VEIGA, TAVARES e MAGALHÃES, 2007).

A despeito da importância patrimonial, Silva e Mancini (2008) relatam que a concentração de atividades diversificadas, com tendências globalizantes e a consequente eliminação do uso residencial nos centros históricos das grandes cidades tem sido responsáveis pela falta de afetividade e de identidade dos moradores com o lugar. Em uma recente pesquisa a respeito da percepção do patrimônio cultural art déco de Goiânia, as autoras apontaram que poucas pessoas fazem alguma ligação entre o patrimônio arquitetônico e a história da cidade e quando o fazem destacam, principalmente, os aspectos negativos, caracterizando os prédios como velhos, feios e sem cores. Tal situação enfatiza a necessidade de políticas de revitalização e conservação do patrimônio arquitetônico do centro histórico de Goiânia, a fim de torná-lo mais vivo para as pessoas e, especialmente, possibilitar o reconhecimento da identidade cultural goianiense. Seu estudo significa o resgate da memória histórica e artística nacional, presente de forma extensiva em todas as regiões do país, cujo número parece permanecer incomparavelmente superior à produção de qualquer outro estilo (GOIÂNIA ART DÉCO, 2010).

\section{OBJETIVO}

Este trabalho tem como objetivo apresentar um estudo de caso que consiste no procedimento utilizado para a inspeção e o mapeamento de manifestações patológicas dos revestimentos em argamassa do tipo reboco lavado, de um importante monumento art déco localizado na cidade de Goiânia-GO, a Torre do Relógio. $O$ estudo visou também levantar as causas e apontar diretrizes voltadas à terapia das manifestações patológicas identificadas nos revestimentos estudados.

\section{METODOLOGIA}

O estudo de caso foi realizado na Torre do Relógio, monumento em estilo art déco o qual é revestido de um tipo de reboco lavado. A metodologia proposta para a inspeção do objeto de estudo, apoiou-se, especialmente, em: (1) inspeção visual, (2) documentação fotográfica, (3) ensaios por percussão e (4) ensaios de esclerometria de pêndulo.

\subsection{CARACTERIZAÇÃO DO OBJETO DE ESTUDO}

A Torre do Relógio, conforme pode ser visto na Figura 1, é um monumento no estilo art déco localizado no centro de Goiânia-GO, no início da Avenida Goiás, entre o monumento ao Bandeirante e o Coreto. Considerado um dos mais antigos pontos de referência da cidade, teve sua 
construção iniciada em 1940, mas somente houve a inauguração em julho de 1942. A principal intervenção na obra ocorreu em 1998, com pintura de esmalte nas esquadrias, recuperação da parte interna e manutenção no relógio. Atualmente o monumento se encontra sob a proteção da Prefeitura Municipal (GOIÂNIA ART DÉCO, 2010).

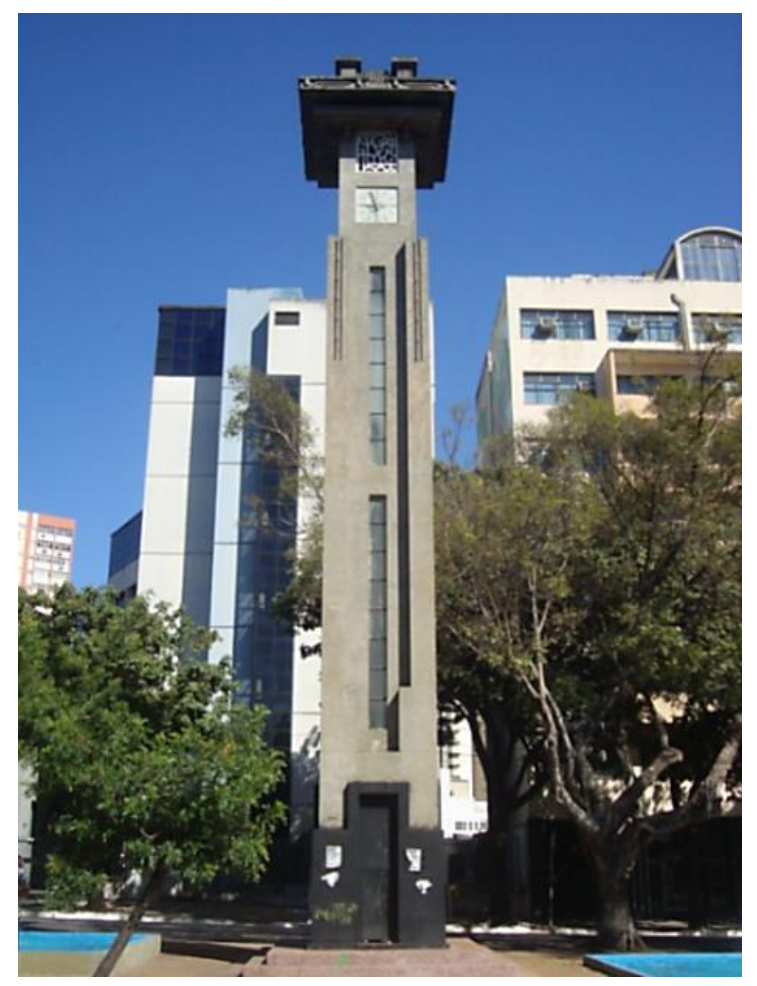

FIGURA 1: Torre do Relógio em Goiânia.

Com cerca de 15 metros de altura, a torre é revestida em reboco lavado, apresentando cor natural e elevada presença de mica, conforme ilustrado na Figura 2 (a). Ao longo de sua extensão, divide-se em cinco partes por meio de frisos, sendo que todos eles, com exceção do inferior, são equidistantes. Somente em uma pequena porção da parte inferior do monumento, ao redor da porta, o revestimento é de argamassa com acabamento em pintura com tinta preta. No eixo da torre existem esquadrias de vidro leitoso transparente. As portas são metálicas, pintadas com tinta esmalte e, no alto da torre, localizam-se os relógios e elementos vazados, ambos metálicos, conforme ilustrado na Figura 2 (b). A torre é constituída por quatro faces, sendo todas elas iguais.

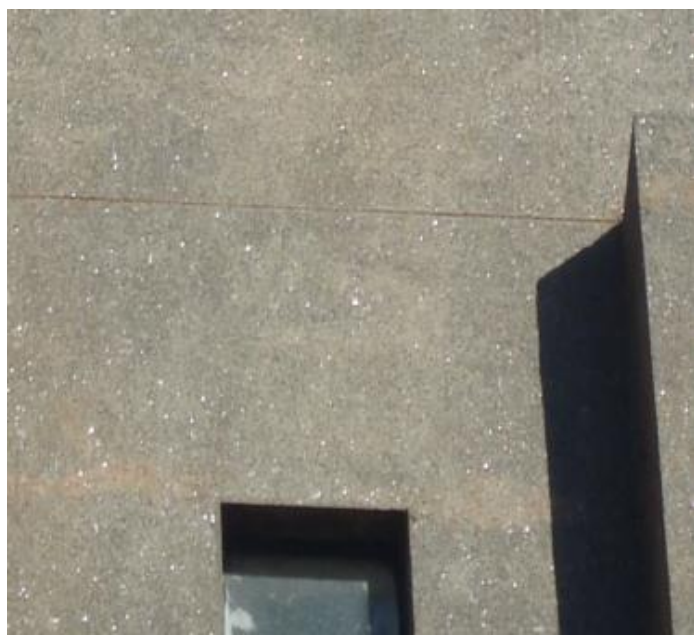

(a)

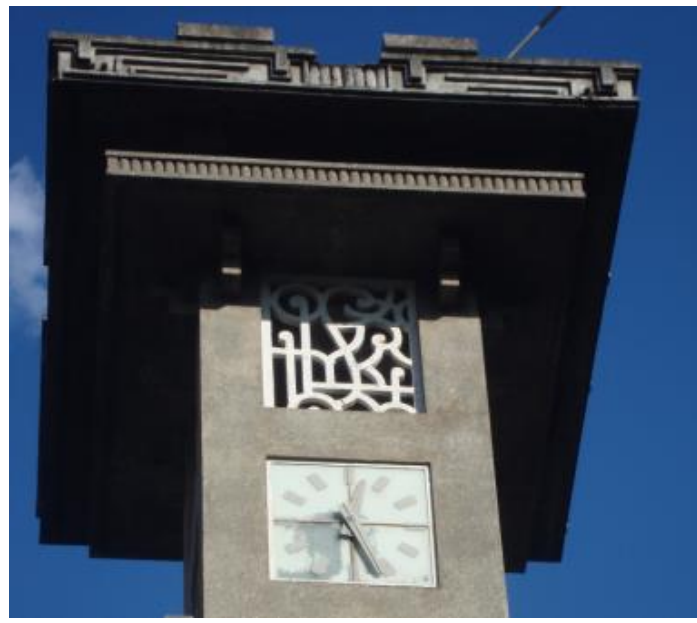

(b)

FIGURA 2: Detalhes da Torre do Relógio (a): Aspecto do revestimento em reboco lavado apresentando brilho característico da mica; (b): Vista superior da torre com a presença de frisos, esquadrias e o relógio.

\subsection{PROCEDIMENTO EMPREGADO NA FASE DE INSPEÇÃO VISUAL}

A inspeção visual da Torre do Relógio foi realizada em três dias distintos e teve como objetivo principal o mapeamento do monumento para o levantamento das manifestações patológicas, além de serem observados aspectos relacionados aos tipos de materiais utilizados.

Foi estabelecido que a inspeção fosse realizada por face, as quais foram denominadas de VISTA SUL, VISTA OESTE, VISTA NORTE e VISTA LESTE, a fim de mapear a ocorrência de manifestações patológicas, entre elas: sujidade, manchas de oxidação, fissura/fendas e 
desagregação superficial, e o resultado da observação visual de cada uma das faces registrado em croquis. Foram calculadas, por meio do software autocad ${ }^{\circledR}$, as medidas individuais das manchas mapeadas em metro quadrado, sendo o índice de manchas de sujidade em cada face, o resultado do somatório das áreas com problema dividido pela área total da face.

Procedimento semelhante foi adotado para o cálculo do índice de fissuração, mas ao invés de área, foi considerado o somatório das medidas individuais do comprimento das fissuras, registradas em metro linear e este valor foi dividido pela área total da face.

O posicionamento das vistas foi uma consideração aproximada, pois existe um leve desvio dos eixos do monumento em relação ao norte magnético, conforme pode ser visualizado na Figura 3.

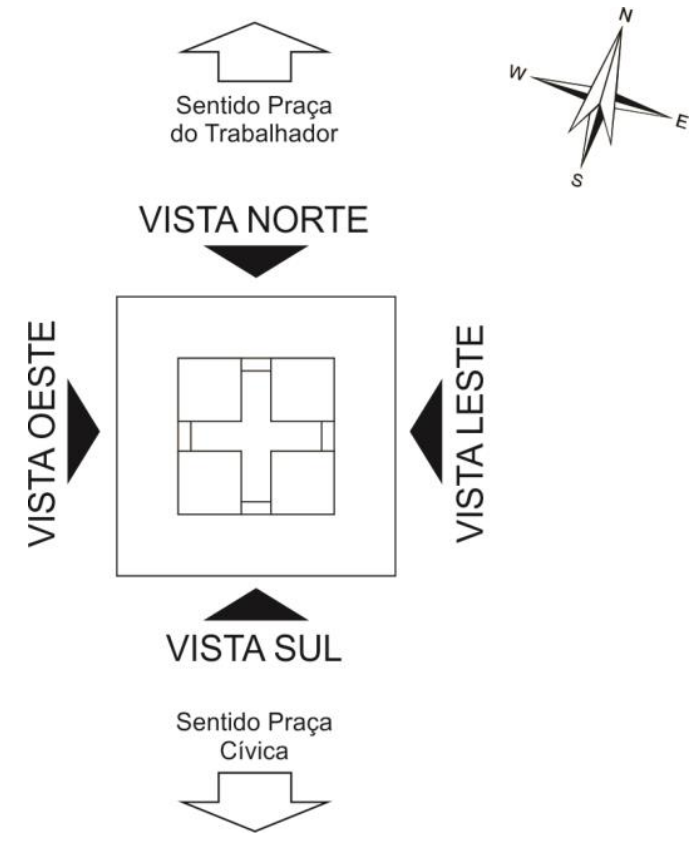

FIGURA 3: Planta baixa representando as quatro faces da edificação distribuídas conforme o estudo.

\subsection{PROCEDIMENTO EMPREGADO DOCUMENTAÇÃO FOTOGRÁFICA}

Concomitantemente à fase de inspeção visual foi realizado um registro fotográfico com 338 fotografias da torre, tiradas tanto no período matutino como no vespertino, com o intuito de confrontar e dirimir possíveis dúvidas sobre os detalhes do mapeamento observados durante a inspeção, devido aos diferentes sombreamentos das vistas nos distintos horários. As fotografias foram tiradas em alta resolução, igual ou superior a 7 megapixels, permitindo assim a ampliação digital quando necessário dirimir dúvidas relativas às manifestações patológicas.

\subsection{PROCEDIMENTO DO ENSAIO DE PERCUSSÃO}

A percussão dos revestimentos foi realizada de acordo com o prescrito na NBR 13749 (ABNT, 1996) por meio de sucessivos impactos leves, não contundentes na superfície inspecionada com instrumento de madeira. $\mathrm{O}$ ensaio foi realizado em toda a parte inferior acessível da torre revestida com reboco lavado e os revestimentos foram mapeados nas quatro faces; as partes que apresentaram som cavo durante $a$ inspeção foram consideradas regiões comprometidas.

\subsection{PROCEDIMENTO DO ENSAIO DE ESCLEROMETRIA DE PÊNDULO}

O ensaio de esclerometria de pêndulo foi realizado segundo as recomendações do RILEM TC 127-MS D.7:1998 e Alves (2009), sendo utilizado para determinação da dureza superficial do revestimento o índice esclerométrico - IE (índice de impacto não absorvido pelo substrato, que é registrado pelo esclerômetro - grandeza adimensional). Foi utilizado um equipamento de marca E.O. Schmidt, modelo PT.

Para este ensaio foram feitas doze leituras por face (vista), sendo seis em cada lado, e o índice esclerométrico obtido por meio do resultado da média aritmética dos pontos onde foram realizadas as leituras. As regiões supostamente comprometidas foram desconsideradas no cálculo da média.

\section{RESULTADOS}

A inspeção visual realizada na Torre do Relógio revelou que o monumento encontra-se deteriorado, com a existência de diversas manifestações patológicas por toda a sua extensão, sendo o grau de intensidade variável, conforme a vista analisada. Os problemas observados foram sujidade, manchas de oxidação, fissuras/fendas e desagregação superficial; alguns trechos já se encontravam reparados quando da 
inspeção.

Na Figura 4 tem-se uma visão geral do mapeamento realizado nas quatro vistas da torre com a identificação das manifestações patológicas encontradas; os casos mais relevantes são analisados e discutidos minuciosamente na sequência.

Após o mapeamento, observou-se que a VISTA OESTE e a VISTA LESTE são as que se encontram em melhor estado de conservação, principalmente, a VISTA LESTE. Na VISTA NORTE são mais visíveis as áreas aonde foram feitos os serviços de reparos em fissuras. A VISTA SUL e a VISTA NORTE apresentaram maior presença de sujidades do que as demais.

A sujidade consiste no recobrimento dos revestimentos com poeiras, fuligem e outras partículas poluentes existentes em suspensão na atmosfera, cujas principais causas relacionam-se com escorrimento da água da chuva nas superfícies, com a orientação da fachada em relação aos principais agentes climáticos (vento e sol), com a textura do revestimento, entre outras (MAGALHÃES, 2002).

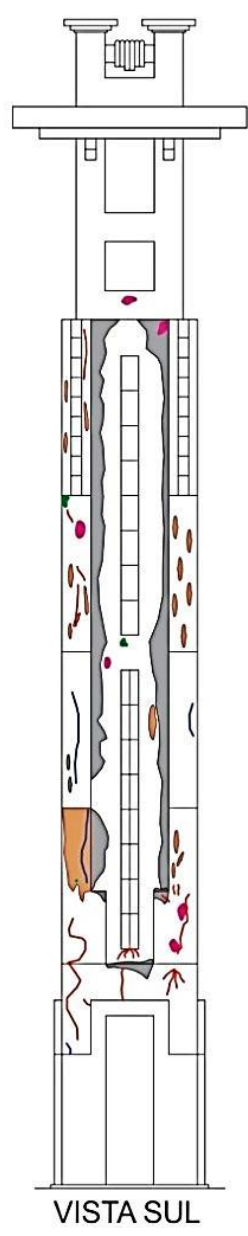

Sujidade

Reparos Localizados

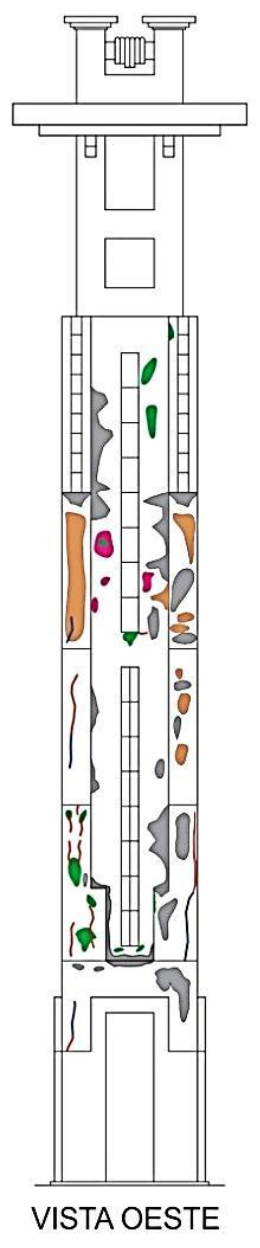

Fissura Reparada

Fissura
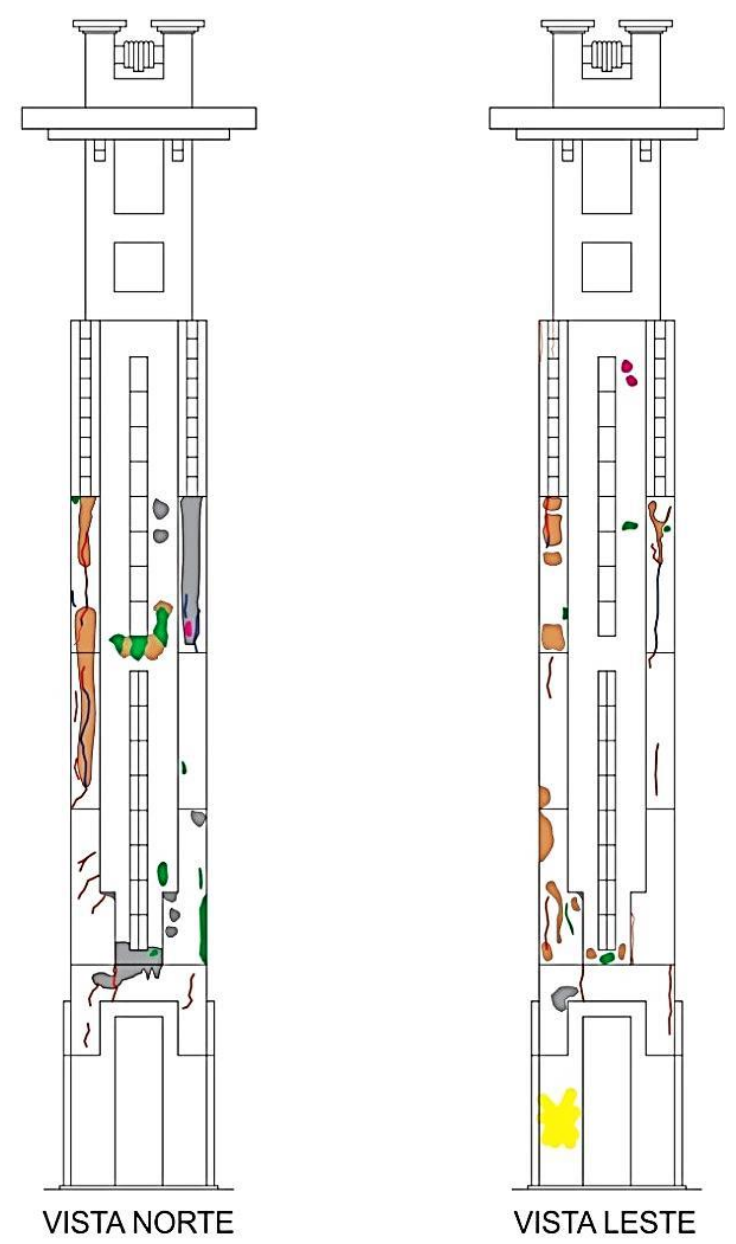

VISTA LESTE

Pichação

Manchas de Oxidação

Desagregação

FIGURA 4: Vista geral do mapeamento da Torre do Relógio. 
Conforme relatam Melo Júnior et al. (2011), além da natureza da superfície, que por sua constituição fornece material orgânico que pode ser utilizado como fonte de alimento para alguns organismos, o crescimento de microrganismos (fungos, bactérias, organismos fototróficos e líquens) em fachadas pode ocorrer devido aos aspectos climáticos, que irão influenciar na predominância de determinada espécie, no transporte e no padrão de crescimento desses organismos, ou então, ser decorrente da ineficiência de elementos de fachadas (pingadeiras de janelas e platibandas) no escoamento de água. $A$ má execução ou ausência de detalhamento em projetos destes elementos contribui constantemente com o manchamento de fachadas pelo escorrimento preferencial de água de chuva, condição essencial para o crescimento de fungos e bactérias.

Foi verificada alta incidência de manchas de sujidade no monumento as quais, de forma geral, apresentaram um lavado regular, conforme ilustrado na Figura 5. Tal situação corrobora a teoria de que as superfícies que apresentam textura rugosa, tais como alvenarias de tijolos e pedras, concreto aparente e reboco lavado, são mais susceptíveis a esse tipo de anomalia, principalmente, em regiões com incidência de poluição, como é o centro de Goiânia (MELO JÚNIOR, 2010). Logo, quanto maior for a rugosidade do reboco, maior será a deposição de partículas transportadas pelo vento na superfície do revestimento.

Magalhães (2002) destaca que no caso da superfície ser mais porosa e mais rugosa, favorece uma maior superfície específica para o depósito de poeiras e outras sujidades, dificultando e inibindo as ações de limpeza por simples lavagem ou pela própria ação da chuva; por outro lado, contribui para a diversificação dos caminhos de escorrimento espalhando a sujidade.

A dureza dos materiais também interfere nas sujidades, pois é a característica deles que irá determinar se as partículas irão aderir ou não ao substrato. A mesma situação ocorre no choque das gotículas de água contra os paramentos, podendo ser ou não absorvidas pelo substrato, ou então, resultarem no escorrimento de água sobre as superfícies (MELO JÚNIOR, 2010).

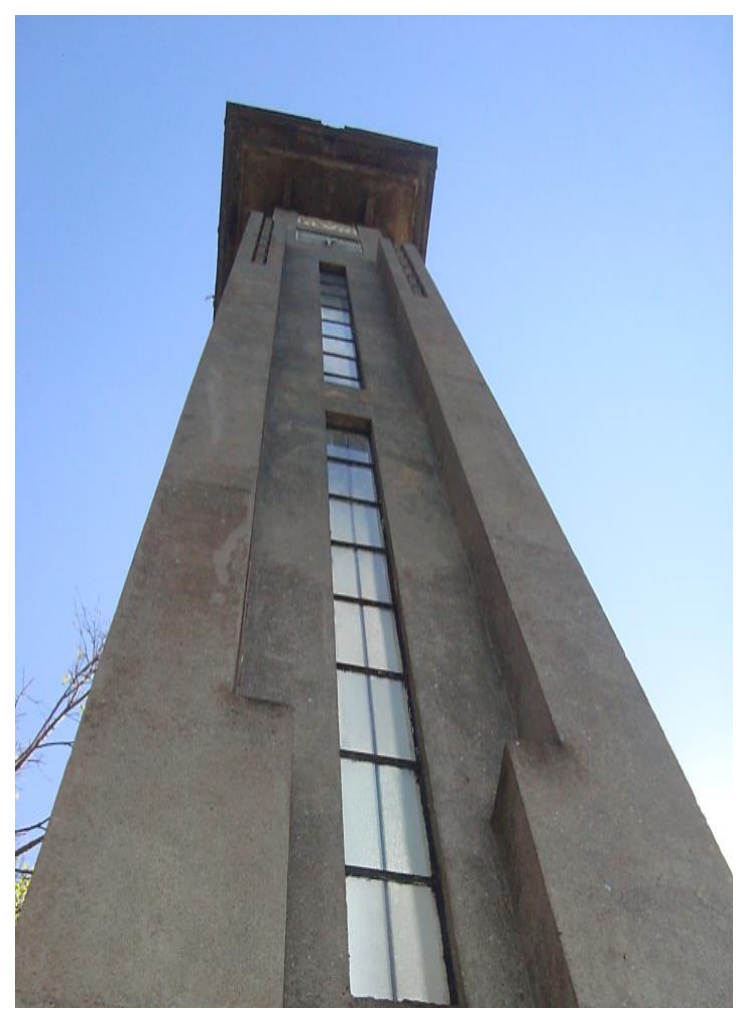

FIGURA 5: Exemplo de manchas de sujidade com lavado regular distribuídas ao longo da VISTA SUL.

Além das manchas escuras de sujidade existentes ao longo da torre, observou-se, durante a inspeção, a presença de sujidades do tipo lavado sujo, que ocorrem sob a ação do escorrimento de superfícies horizontais muito sujas, onde a água arrasta grandes quantidades de partículas, redepositando-as, posteriormente, em planos verticais e inclinados (Melo Júnior, 2010), como ilustrado na Figura 6.

A VISTA SUL, a VISTA OESTE e a VISTA NORTE apresentaram lavado sujo, sendo praticamente ausente a presença dessa anomalia na VISTA LESTE. Conforme ilustrado na Figura 6 existe uma forte presença do lavado sujo na VISTA NORTE e, de acordo com Melo Júnior (2010), a fachada Norte é a que mais recebe a incidência de chuva em Goiânia, aumentando esse efeito. Observando-se o mesmo elemento arquitetônico, porém na VISTA LESTE, não se vê essa anomalia, conforme ilustrado na Figura 7. 


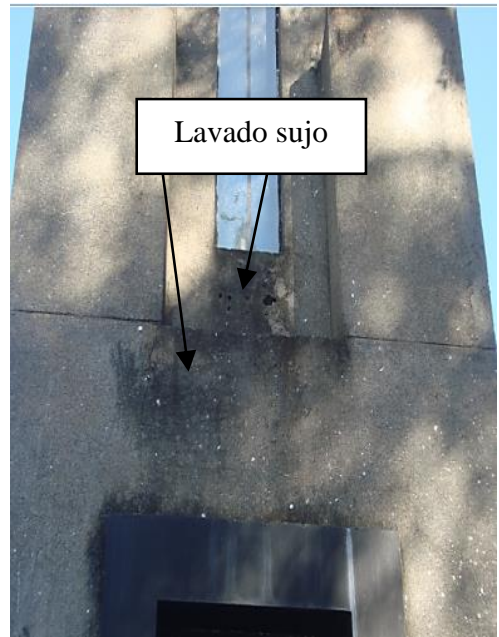

FIGURA 6: Forte presença de lavado sujo localizado na VISTA NORTE.

A inspeção também demonstrou a ocorrência de grande quantidade de fissuras no monumento. Observou-se que elas são, em grande parte, longitudinais sendo que algumas já passaram por processo de reparo. Entretanto, constatou-se durante a inspeção, que tal medida de intervenção não tem sido eficiente, pois em algumas partes do revestimento as fissuras não foram totalmente fechadas ou reabriram novamente, conforme pode ser visualizado na Figura 8. Além disso, em termos estéticos, o aspecto é desagradável para o expectador que ao observar o monumento percebe os reparos de maneira destacada.

Durante o mapeamento também foram identificados na VISTA LESTE dois casos de aberturas de fendas. Conforme ilustrado na Figura 9, possivelmente, a causa desta fenda está relacionada à retração do reboco e ou às movimentações higrotérmicas entre o reboco e a

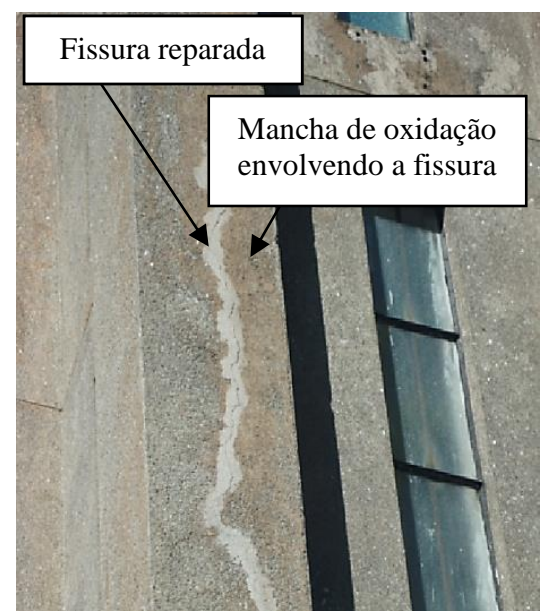

FIGURA 8: Exemplo de fissura longitudinal reparada localizada na VISTA NORTE.

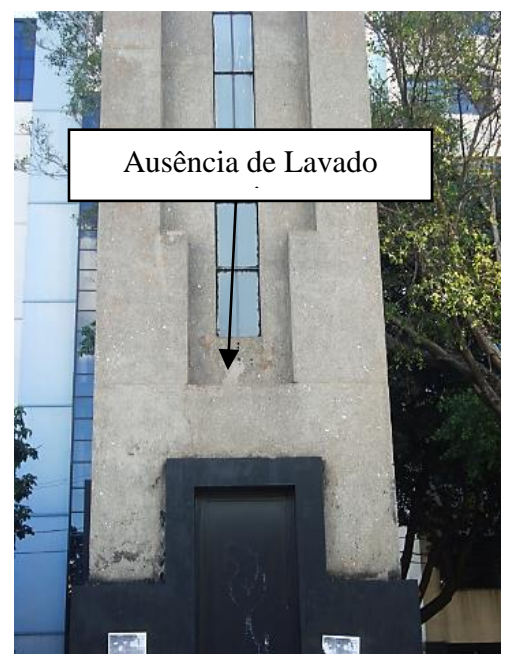

FIGURA 7: Ausência de lavado sujo localizado na VISTA LESTE.

base. Segundo Magalhães (2002), quando o suporte, ou camada precedente, por ser mais rígido, restringe a retração do reboco, instalam-se no plano de aderência entre o reboco e o suporte, tensões de tração elevadas, que podem dar origem ao aparecimento de fendas. Estas ocorrem na espessura total da camada de reboco e, nos casos mais graves, são acompanhadas de perda de aderência ao suporte ou à camada precedente, na região próxima às fendas, como ocorreu na região ilustrada. Além disso, observa-se que a abertura da fenda está localizada na quina do revestimento. Segundo Magalhães (2002), as fendas que surgem nas quinas originam-se da concentração de tensões existentes nestes pontos ocorrendo, com maior frequência, quando há movimentos diferenciais mais significativos entre o revestimento e o suporte.

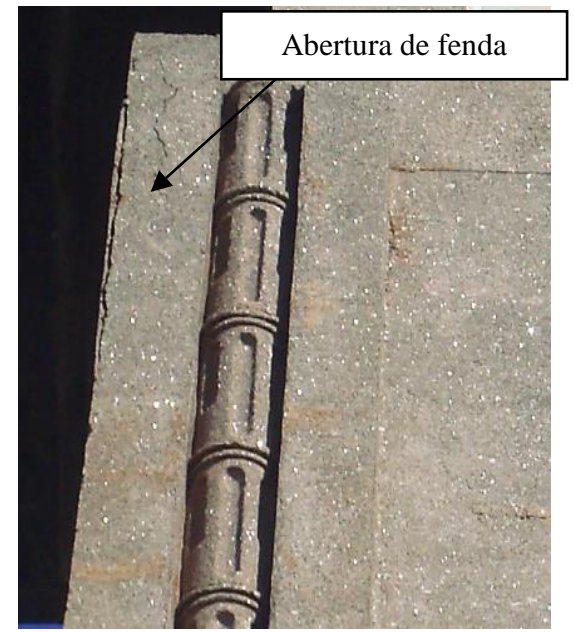

FIGURA 9: Exemplo de abertura de fenda no revestimento com a perda de aderência ao suporte. 
Além de fissuras longitudinais, foram identificadas fissuras em forma de mapa em locais específicos, como por exemplo, abaixo da esquadria inferior, na VISTA SUL, e também na VISTA LESTE, na parte superior direita, conforme ilustrado na Figura 10.

As fissuras mapeadas podem ter origem na retração plástica da argamassa de revestimento. De acordo com Carasek (2010), a retração de produtos à base de cimento está ligada à variação do volume, principalmente, para as argamassas que apresentam relações água/aglomerante em teores elevados. A retração dá-se pelas reações de hidratação do cimento, porém, a principal causa é a perda de água para o meio ambiente por secagem. Para as regiões de clima quente, seco e de ventos fortes, o processo de perda de água é mais severo, o que não permite que a argamassa possua tempo suficiente para atingir resistência à tração e suportar as tensões internas na argamassa, causando, assim, a fissuração do revestimento. Já as fissuras longitudinais podem estar associadas a um processo de corrosão de armaduras existentes na base do revestimento (estrutura de concreto). A corrosão das armaduras gera expansão pelo acúmulo de produtos corrosivos no entorno das barras de aço, fissurando o concreto. Outra característica da corrosão das armaduras é a presença de manchas ferruginosas na superfície, decorrentes da dissolução, percolação pela estrutura porosa e incidência na superfície desses produtos de corrosão (CASCUDO, 1997).

A inspeção revelou ainda um fato interessante: a presença de uma fissura longitudinal em três das quatro vistas analisadas, conforme demonstrado nas Figuras 11 ( $a$, b e c). Embora não sejam idênticas, chamam a atenção porque se assemelham tanto na forma quanto na posição.

Para melhor visualização dos resultados e tendo como referência os mapeamentos esquematizados anteriormente, foram calculados o índice de manchas de sujidade e o índice de fissuração das vistas da Torre do Relógio, conforme ilustrado na Figura 12.

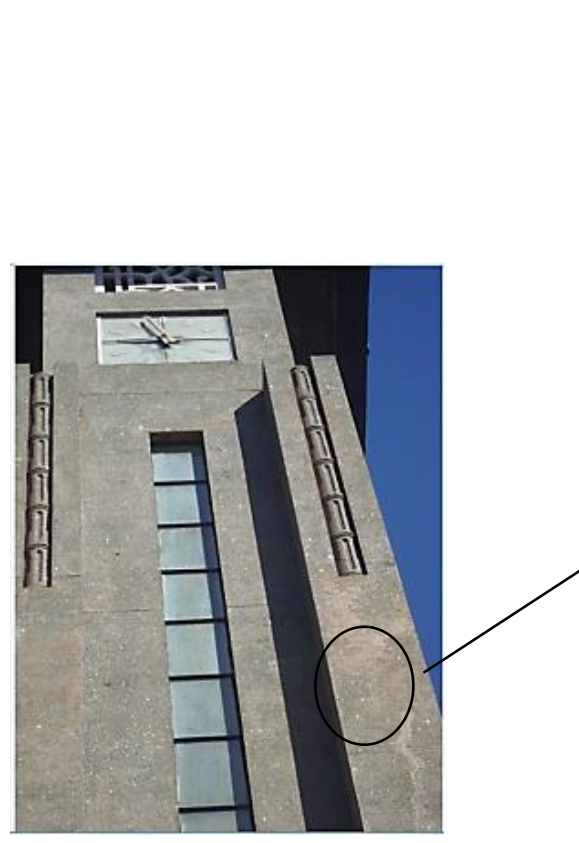

(a)

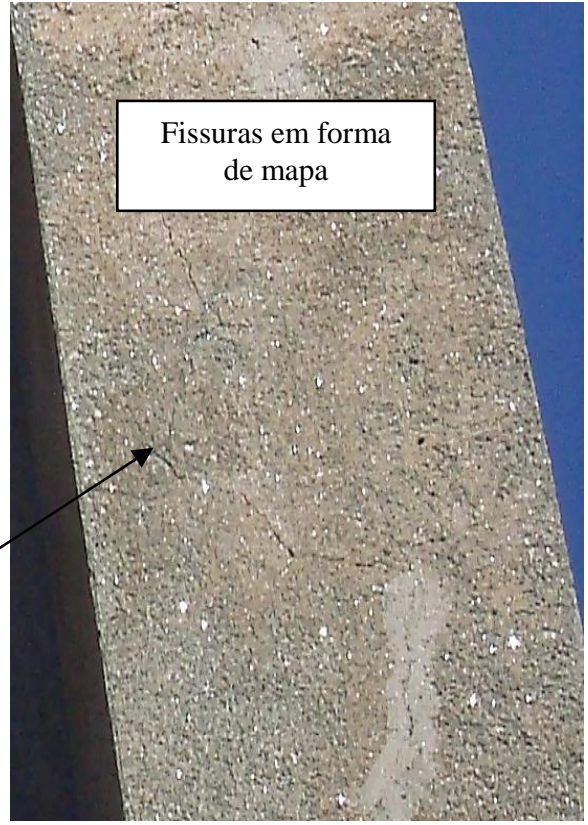

(b)

FIGURA 10: Região com a presença de muitas fissuras mapeadas na VISTA LESTE - (a) Vista geral; (b) Vista ampliada. 


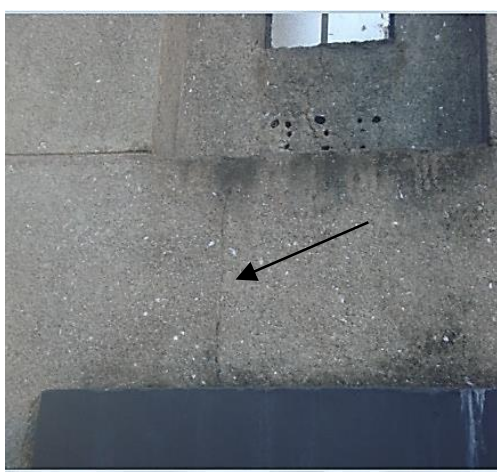

(a) VISTA SUL

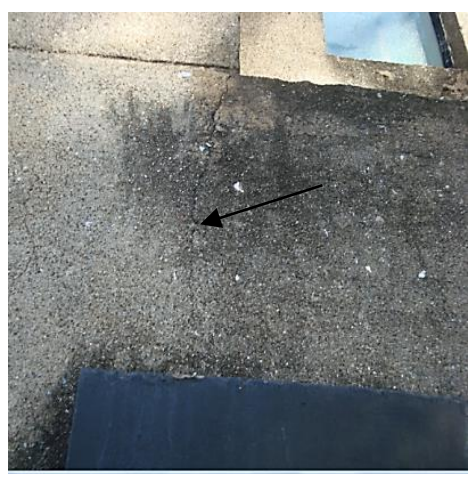

(b) VISTA NORTE

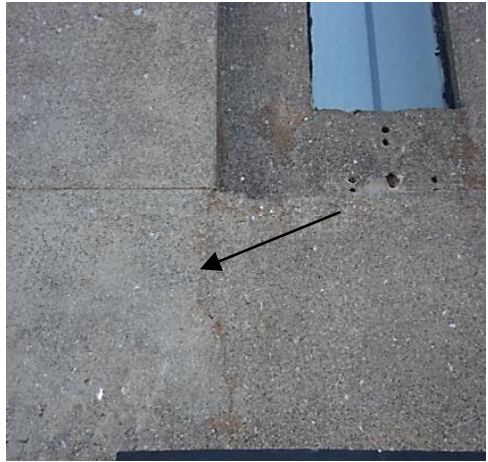

(c) VISTA LESTE

FIGURA 11: Fissuras longitudinais presente em três vistas do monumento.

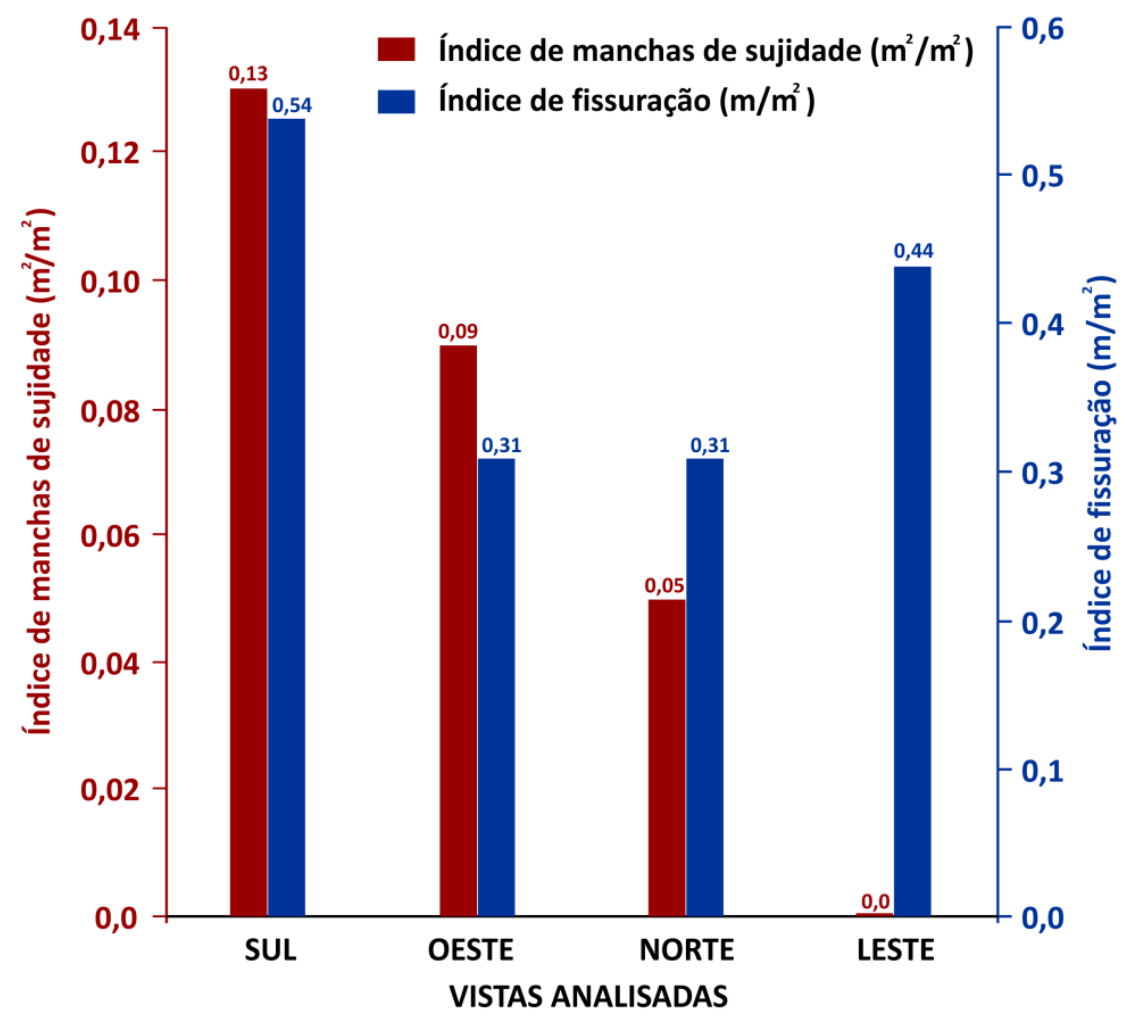

FIGURA 12: Índice de manchas de sujidade e índice de fissuração das quatro vistas analisadas.

Tendo em vista que a área total inspecionada de cada face do monumento é 17,27 $\mathrm{m}^{2}$, observa-se que a VISTA SUL apresentou o maior índice de manchas de sujidade $\left(0,13 \mathrm{~m}^{2} / \mathrm{m}^{2}\right)$ e a VISTA LESTE, o menor valor, praticamente sem manchas de sujidade. Na pesquisa de Melo Júnior (2010), a situação foi semelhante, ou seja, a formação de manchas ocorreu na maioria dos casos estudados por ele, nas fachadas sul. A hipótese apresentada pelo autor e que, possivelmente, possa explicar também a situação verificada na Torre do
Relógio, é de que no período do ano em que acontecem poucas chuvas na cidade de Goiânia, prevaleçam os ventos nos sentidos S, SE e SO, os quais depositam sobre as fachadas sul, o material particulado. Pela presença de água por umidade, ou seja, pela condensação que geralmente ocorre em fachadas voltadas à direção sul, os poluentes encontram superfícies favoráveis à adesão e no período de chuva estas fachadas recebem menor quantidade de água, conforme comprovado pelos índices de chuva dirigida apresentados por 
Melo Júnior (2010), causando o lavado insuficiente nas superfícies e, consequentemente, acentuando a formação das manchas. Ademais, no trabalho de Melo Júnior et al. (2011) foi identificada, por meio de análises microbiológicas, a presença de fungos em elementos do revestimento das fachadas voltadas para o sul. Isto é explicado, pois estes microrganismos não necessitam de energia solar para o seu crescimento. Assim, acredita-se que parte das manchas observadas na VISTA SUL da torre são apenas sujidade, mas parte delas são fungos.

Quanto ao índice de fissuração, o maior valor encontrado também foi observado na VISTA SUL $\left(0,54 \mathrm{~m} / \mathrm{m}^{2}\right)$ e os menores, nas vistas OESTE e NORTE, ambos coincidentemente $\left(0,31 \mathrm{~m} / \mathrm{m}^{2}\right)$, conforme ilustrado na Figura 12. O maior comprimento de fissura registrado foi $2,0 \mathrm{~m}$, localizado na VISTA SUL, e o menor, 0,1 m, localizado na VISTA OESTE.

Cabe ressaltar-se que o método proposto possui algumas limitações e que, por esta razão, os valores quantificados das manifestações patológicas são aproximados. Primeiramente, porque, tanto para a determinação da área das manchas de sujidade quanto para o cálculo do comprimento das fissuras, estas manifestações quantificadas estão limitadas à visualização na distância adotada para a observação. Ademais, as fissuras mapeadas e quantificadas possuem diferentes aberturas, contudo este parâmetro não foi quantificado e considerado no método.

As manchas de oxidação estão presentes em todas vistas analisadas e provavelmente são causadas pela corrosão de armaduras de elementos metálicos na base do revestimento ou mesmo pela presença de impurezas nas areias que, por meio de uma reação de oxidação, formam compostos expansivos que mancham a superfície dos rebocos - hidróxidos de ferro e óxidos de ferro hidratados (CARASEK, 2010). Na VISTA OESTE e na VISTA NORTE as manchas são mais pontuais, localizandose em determinadas partes do revestimento. Em algumas partes da superfície do revestimento, foi possível vê-las associadas a outras anomalias, como por exemplo, envolvendo regiões fissuradas, conforme ilustrado anteriormente na Figura 8.

Nas vistas SUL e LESTE, observou-se ainda, o fenômeno patológico de perda de coesão ou desagregação superficial que, de acordo com Magalhães (2002), consiste na separação dos componentes do reboco seguida por uma considerável perda das partículas que o compõem, transformando-o em um material frágil e susceptível à degradação.

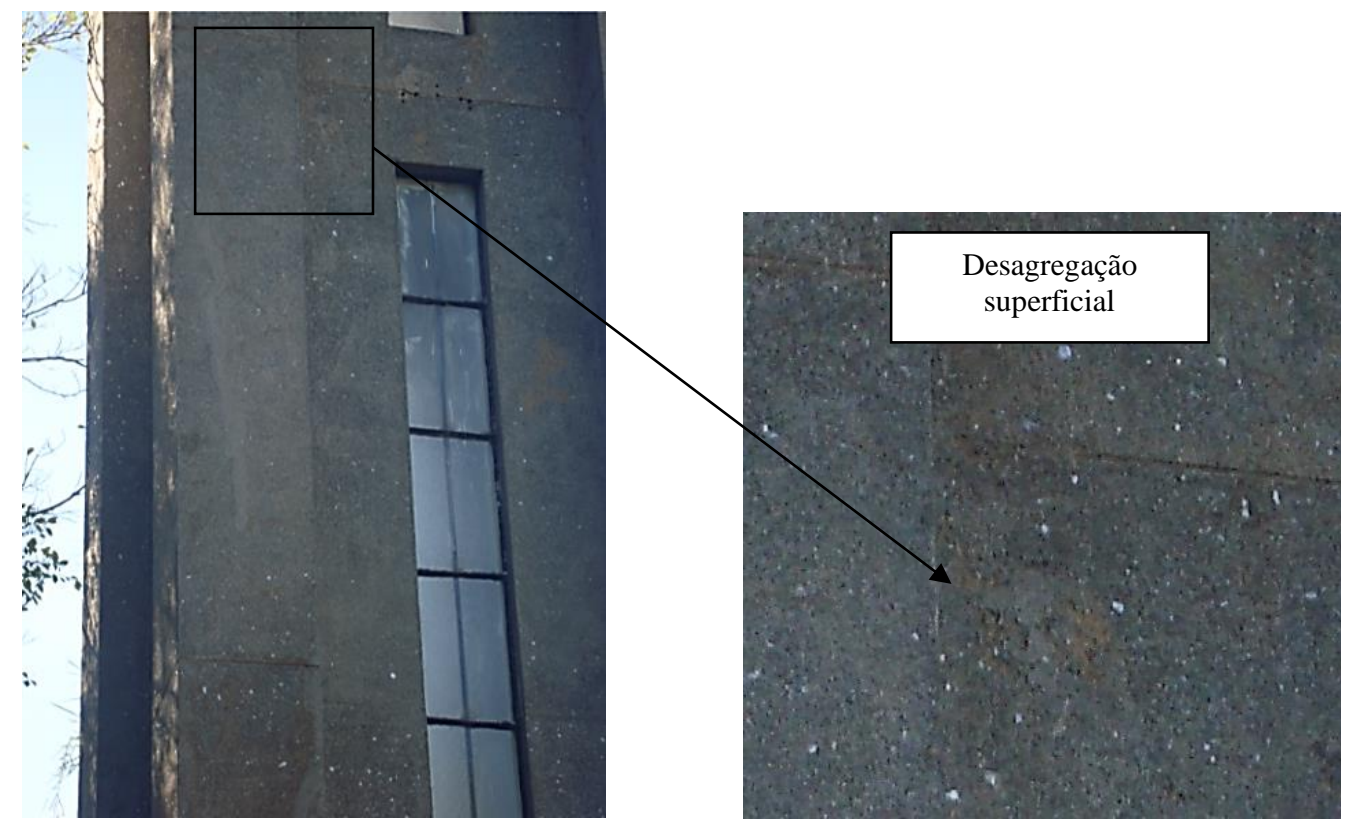

FIGURA 13: Trecho localizado na VISTA SUL onde se manifesta o fenômeno patológico de desagregação. 
Observou-se, por fim, que algumas intervenções pontuais foram realizadas na torre, certamente, para conter o avanço da deterioração.

De maneira geral, o resultado do ensaio de percussão é um indicativo de que o revestimento apresenta ou não boa aderência. No presente estudo, quanto aos resultados do ensaio de percussão, mostrados nas Figuras 14 (a, b, c e d), foi verificado que o reboco de todas as vistas apresentou problemas de aderência. As regiões marcadas nas ilustrações expressaram locais de som cavo denotando a anomalia.

Observou-se que a VISTA NORTE apresentou uma extensa área comprometida, distribuída por toda a superfície analisada, seguida da VISTA SUL, que apesar de ter apenas um ponto indicativo de descolamento, possui considerável dimensão. Já nas VISTAS LESTE e OESTE também foram identificadas regiões com problemas de aderência que, embora menores em sua dimensão, se encontram mais distribuídas na superfície do revestimento. Dada a grande incidência de fissuração do reboco, é bem possível que vários outros pontos da torre, não analisados por esse ensaio, também se encontrem descolados.

No Quadro 1 são apresentados os resultados do ensaio com o esclerômetro de pêndulo.

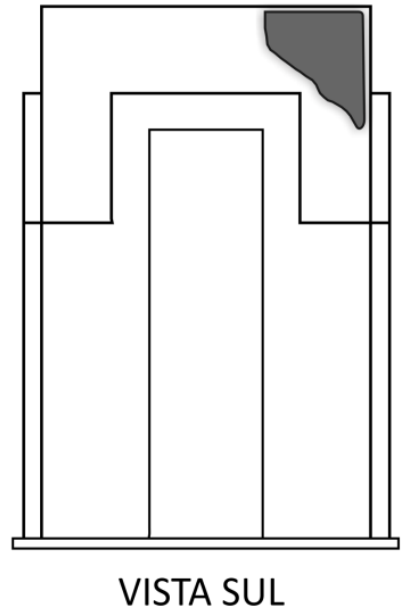

(a)

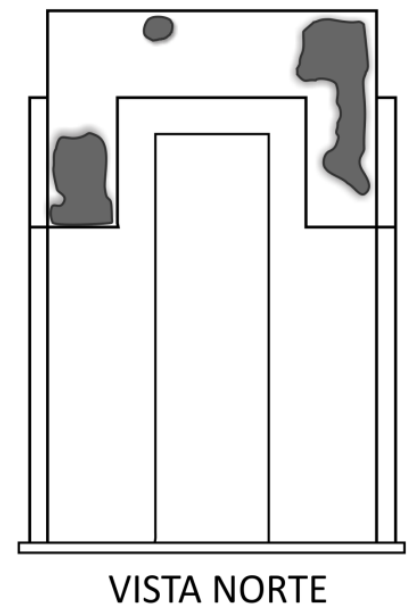

(c)

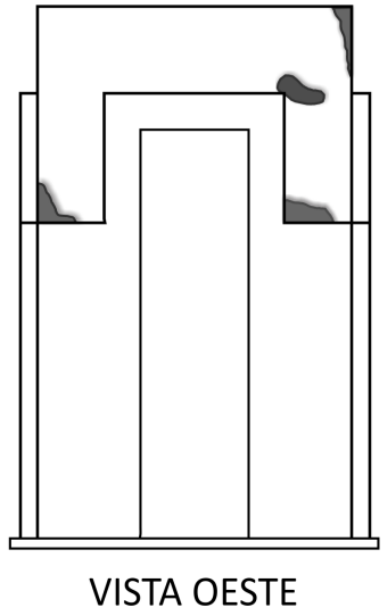

(b)

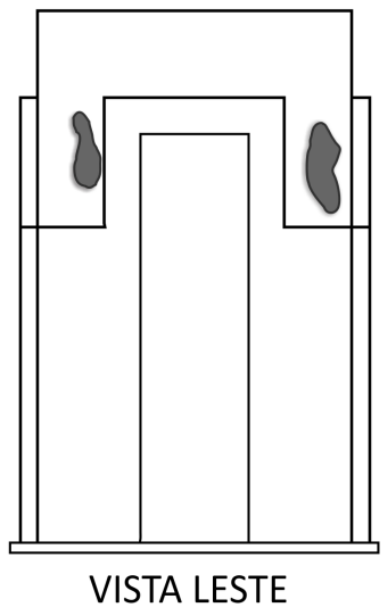

(d)

FIGURA 14: Resultado do teste de percussão mostrando regiões que apresentaram problemas de aderência:

(a) VISTA SUL, (b) VISTA OESTE, (c) VISTA NORTE e (d) VISTA LESTE. 


\begin{tabular}{|c|c|c|c|c|c|}
\hline Vista & Lado & IE & Média & Médias globais & Situação \\
\hline \multirow{2}{*}{ SUL } & Esquerdo & $\begin{array}{l}\text { S.L. } \\
\text { S.L. } \\
\text { S.L. } \\
\text { S.L. } \\
\text { S.L. } \\
\text { 82,0 }\end{array}$ & N.C. & \multirow[b]{2}{*}{ - } & \multirow{2}{*}{$\begin{array}{l}\text { Praticamente toda } \\
\text { sem leitura }\end{array}$} \\
\hline & Direito & $\begin{array}{l}\text { S.L. } \\
\text { S.L. } \\
78,5 \\
\text { S.L. } \\
\text { S.L. } \\
\text { S.L. }\end{array}$ & N.C. & & \\
\hline \multirow{2}{*}{ OESTE } & Esquerdo & $\begin{array}{l}\text { S.L. } \\
68,0 \\
\text { S.L. } \\
\text { S.L. } \\
73,0 \\
88,5\end{array}$ & 76,5 & \multirow{2}{*}{78,25} & \multirow{2}{*}{$\begin{array}{c}\text { Metade das leituras } \\
\text { obtidas }\end{array}$} \\
\hline & Direito & $\begin{array}{l}\text { S.L. } \\
\text { S.L. } \\
\text { S.L. } \\
84,0 \\
71,5 \\
84,5\end{array}$ & 80,0 & & \\
\hline \multirow{2}{*}{ NORTE } & Esquerdo & $\begin{array}{l}75,0 \\
\text { S.L. } \\
67,5 \\
\text { S.L } \\
\text { S.L. } \\
\text { S.L. }\end{array}$ & 71,3 & \multirow{2}{*}{71,7} & \multirow{2}{*}{$\begin{array}{c}\text { Metade das leituras } \\
\text { obtidas }\end{array}$} \\
\hline & Direito & $\begin{array}{l}\text { S.L. } \\
65,0 \\
\text { S.L. } \\
74,0 \\
77,5 \\
\text { S.L. }\end{array}$ & 72,2 & & \\
\hline LESTE & Esquerdo & $\begin{array}{c}114,0 \\
91,0 \\
83,0 \\
\text { S.L. } \\
90,0 \\
81,5 \\
\end{array}$ & 91,9 & 82,9 & $\begin{array}{c}\text { Maior dureza } \\
\text { superficial e rigidez }\end{array}$ \\
\hline
\end{tabular}

\section{Legenda:}

S.L. = sem leitura; significa que não foi obtida leitura devido não ter havido reflexão após o impacto, possivelmente, pelo descolamento ou baixa resistência do reboco na região ensaiada;

N.C.= não calculado, devido ao pequeno tamanho da amostra;

*IE - adimensional.

Verificou-se, após a análise dos dados, que o maior índice esclerométrico foi 82,9, registrado na VISTA LESTE, seguido da VISTA OESTE, com 78,25 e VISTA NORTE, com 71,7. Na VISTA SUL, do lado esquerdo, só foi encontrado apenas um ponto onde foi possível se fazer a leitura, por isso, não foi calculada a média nessa face. Correlacionando esse resultado com o ensaio de percussão, percebe-se coerência nos resultados, pois a VISTA LESTE apresenta bom estado de aderência do reboco. Porém, analisando a VISTA OESTE, o resultado converge parcialmente porque, de acordo com o cálculo do IE, subentende-se que esta face esteja descolada, embora pelo ensaio de percussão, a consideração é de que o revestimento ainda esteja bem aderido, pois as áreas mapeadas no ensaio que apresentam som oco são em regiões localizadas, principalmente, nos 
cantos. Para a VISTA SUL, assim como no ensaio esclerométrico, o ensaio de percussão indicou apenas um ponto no revestimento passível de estar descolado, o que sugere mais investigação.

Alves (2009), durante sua pesquisa, encontrou o índice esclerométrico médio para a argamassa mista igual a 55 e para a argamassa industrializada, 71, ou seja, valores bem diferenciados e ambos com baixo coeficiente de variação $(C V=9 \%)$, concluindo que a técnica se mostra eficaz no sentido de caracterizar argamassas de comportamentos distintos. No caso da Torre do Relógio, observa-se que quando foi possível obter algum IE, estes foram mais altos do que os obtidos por Alves (2009). Isto pode ser explicado pelo tipo de revestimento analisado, reboco lavado, que contem agregados com dimensões maiores do que os revestimentos convencionais (que recebem pintura), além de terem na sua superfície os agregados expostos, devido ao processo de lavagem, apresentando maior dureza superficial. A alta variabilidade obtida pode ser explicada pelas regiões descoladas, bem como pela deterioração que o revestimento apresenta no decorrer dos anos, uma vez que o monumento está com quase 72 anos.
No Quadro 2 é apresentada uma síntese dos resultados, a qual busca uma correlação entre alguns fatores estudados nesta pesquisa, para a avaliação do revestimento da Torre do Relógio, quanto às manifestações patológicas mais incidentes e à metodologia de inspeção. $A$ análise é feita por meio de uma escala gradual mostrando três níveis de degradação do revestimento, isto é, pior situação, situação intermediária e melhor situação.

A análise da VISTA SUL demonstrou que ela apresenta a pior situação, ou seja, é a mais deteriorada, tanto em relação ao manchamento, à fissuração e aos descolamentos. Assim como na VISTA OESTE, a inspeção dessa vista também foi prejudicada devido às más condições de visibilidade.

Em seguida, A VISTA NORTE foi a que se apresentou em pior situação, embora em relação às manchas de sujidade e fissuração, os resultados terem sido razoáveis. Contudo, apresentou baixo resultado do índice esclerométrico, indicando problemas de adesão do revestimento ao substrato, fato comprovado também pelo insatisfatório resultado do ensaio de percussão.

\begin{tabular}{|c|c|c|c|}
\hline \multicolumn{2}{|c|}{ QUADRO 2: Síntese dos resultados da avaliação do revestimento da Torre do Relógio. } \\
\hline $\begin{array}{c}\text { Manifestações } \\
\text { patológicas e } \\
\text { metodologia }\end{array}$ & Pior situação & $\begin{array}{c}\text { Situação } \\
\text { intermediária }\end{array}$ & Melhor situação \\
\cline { 2 - 4 } & SUL & LESTE & NORTE/OESTE \\
\hline Fissuração & SUL & OESTE/NORTE & LESTE \\
\hline Manchas de sujidade & NORTE & SUL & LESTE/OESTE \\
\hline Índice esclerométrico & SUL & NORTE/OESTE & LESTE \\
\hline
\end{tabular}


A VISTA OESTE foi a vista mais complexa e difícil de ser analisada. Isso porque encontra-se permanentemente escura, apresentando condições inadequadas de visibilidade que dificultaram a inspeção. Essa situação é agravada pelas árvores presentes no canteiro da avenida, próximas à torre, as quais projetam sombra na mesma. Contudo, essa vista apresentou um bom estado de conservação quando comparada às demais.

Por fim, a VISTA LESTE foi a que apresentou a melhor situação, ou seja, com o revestimento mais conservado. Apresentou problemas de fissuração, contudo apresentou bons resultados nos outros parâmetros. Isto pode ser comprovado pelo alto índice esclerométrico, que indica que o revestimento é bom e ainda está aderido. Esse parâmetro é muito importante tratando-se do reboco lavado, pois indica que houve coesão entre os agregados que o constituem. Quanto às manchas de sujidade percebeu-se uma discreta presença. Melo Júnior et al. (2011) também encontraram, para várias fachadas analisadas na cidade de Goiânia, que as fachadas orientadas para leste eram as menos deterioradas com relação ao manchamento.

Diante do exposto é sugerido, no Quadro 3, um conjunto de medidas e diretrizes gerais para reparo dos problemas observados nos rebocos lavados do estudo de caso.

QUADRO 3 - Diretrizes para recuperação do revestimento

\begin{tabular}{|c|c|}
\hline Manifestação patológica & Proposta de Reparo \\
\hline Fissuras e fendas & $\begin{array}{l}\text { As fendas e fissuras devem ser preenchidas, por meio de espátula, com } \\
\text { uma argamassa de composição semelhante à da argamassa original. } \\
\text { Para tanto, deve ser realizado um estudo de reconstituição de traço da } \\
\text { argamassa original, além de testes in loco para adaptação do } \\
\text { cromatismo. (CASCUDO; CARASEK, 1992; VEIGA; TAVARES; } \\
\text { MAGALHÃES, 2007). }\end{array}$ \\
\hline $\begin{array}{l}\text { Reboco lavado descolado em } \\
\text { bolsões }\end{array}$ & $\begin{array}{l}\text { Reconstituição da aderência por meio de injeção de graute ou calda à } \\
\text { base de cal aérea (VEIGA; TAVARES; MAGALHÃES, 2007). }\end{array}$ \\
\hline Manchas & $\begin{array}{l}\text { A limpeza do reboco lavado pode ser feita por via úmida ou seca. } \\
\text { Limpeza úmida - com jato de água a baixa pressão - } 50 \text { bar para a } \\
\text { remoção de sujidades generalizadas e } 70 \text { bar, com uma inclinação de } \\
45^{\circ} \text { e uma distância de } 15 \text { a } 30 \mathrm{~cm} \text {, para remoção das crostas e de } \\
\text { infestações de origem biológica mais intensas. (Cuidado: testar a } \\
\text { pressão de forma que não danifique o revestimento). } \\
\text { Limpeza a seco - por micro abrasão, nas zonas onde persistirem as } \\
\text { manchas escurecidas e alguma infestação de origem biológica. A } \\
\text { pressão de saída do ar utilizada varia de } 1 \text { a } 2 \text { bar, variável consoante o } \\
\text { suporte e o tipo de incrustação a remover. Um abrasivo que pode ser } \\
\text { utilizado é a farinha de sílica. (CASCUDO; CARASEK, 1992; VEIGA; } \\
\text { TAVARES; MAGALHÃES, 2007) }\end{array}$ \\
\hline Desagregação superficial & $\begin{array}{l}\text { Adotar técnica de consolidação do revestimento: aplicação de um } \\
\text { material que ao penetrar em profundidade, melhora a coesão entre } \\
\text { partículas do reboco desintegrado, suas características mecânicas } \\
\text { (resistência superficial) e a aderência entre as camadas de } \\
\text { revestimentos (umas às outras e com o suporte). Utilizar um dos } \\
\text { seguintes materiais consolidantes: água de cal simples, água de cal } \\
\text { aditivada com pozolanas, soluções à base de silicatos ou } \\
\text { bioconsolidação por meio de bactérias (VILLEGAS, 2003; VELOSA, 2006; } \\
\text { ALVES, 2009). }\end{array}$ \\
\hline
\end{tabular}




\section{CONCLUSÕES}

A metodologia destinada à avaliação do revestimento da Torre do Relógio mostrou-se eficaz, mesmo com as limitações das condições de trabalho.

A realização do mapeamento das vistas comprovou que o monumento encontra-se deteriorado, fato justificado devido à presença de várias manifestações patológicas, principalmente, apresentando um elevado índice de fissuras e manchas de sujidade, além de desagregação e manchas de oxidação no revestimento do mesmo. A VISTA SUL e a VISTA NORTE são as que se encontram em pior estado de conservação, com incidência de muitas anomalias. Em contrapartida, a VISTA OESTE e a VISTA LESTE, são as que estão em melhor situação, estando mais conservadas, especialmente a VISTA LESTE, cujo aspecto visual do reboco lavado parece continuar apresentando durabilidade e resistência, mesmo com o passar dos anos.

\section{REFERÊNCIAS BIBLIOGRÁFICAS}

ABNT - Associação Brasileira de Normas Técnicas. NBR 13749: Revestimento de paredes e tetos de argamassas inorgânicas - Especificação. Rio de Janeiro, 1996.

ALVES, A. S. Estudo da propriedade resistência superficial em revestimentos de argamassa. 2009. $159 \mathrm{f}$ Dissertação (Mestrado em Engenharia Civil) - Escola de Engenharia Civil, Universidade Federal de Goiás, Goiânia, 2009.

BORGES, M. S. Art déco, entre a Tradição e o Moderno. In: II ENCONTRO DE HISTÓRIA DA ARTE, 2006, Campinas, São Paulo. Disponível em $<$ www.ifch.unicamp.br/pos/hs/anais/2006/posgrad/(62). pdf >. Acesso em: junho de 2011.

CARASEK, H. Argamassas. In: ISAIA, G. C. (Org.) Materiais de Construção e Princípios de Ciência e Engenharia de Materiais. São Paulo: IBRACON, 2010, v. 2, p. 893-944.

CASCUDO.O. O controle da corrosão de armaduras em concreto: inspeção e técnicas eletroquímicas. São Paulo, Ed. UFG/PINI, 1997.

CASCUDO, O.; CARASEK, $\mathrm{H}$. Relatório de vistoria técnica para registro do estado atual das fachadas do prédio da Biblioteca Pública Mário de Andrade do município de São Paulo. Trabalho técnico sobre restauração de fachada. São Paulo, 1992.
CORREIA, T. de B. Art déco e indústria - Brasil, décadas de 1930 e 1940. Anais do Museu Paulista: História e Cultura Material. São Paulo, v. 16, n ', p. 47-104, 2008.

CZAJKOWSKI, J (Org.). Guia da arquitetura art déco no Rio de Janeiro. 3. Ed. Rio de Janeiro: Editora: Casa da Palavra, 2000. 164 p. ISBN 85-87220-26-8.

DIAZ, H. E. O art déco no Chile: último estilo acadêmico e primeiro estilo moderno. In: I SEMINÁRIO INTERNACIONAL: ART DÉCO NA AMÉRICA LATINA, 1997, Rio de Janeiro. Anais... Rio de Janeiro: Solar Grandjean de Montigny, PUC/RJ, 1997. 236 p, p. 55-58. ISBN 8586505-01-3.

GOIÂNIA art déco: acervo arquitetônico e urbanístico dossiê de tombamento. Edição 2010. Instituto Casa Brasil de Cultura, 2010. 190 p.

GONÇALVES, M. R. F.; FERNANDES, A. R; LEITE, C. P.; DIAS, A. R. P. Revestimento externo do prédio da Catedral São Francisco de Paula, Pelotas-RS caracterização e identificação de fenômenos patológicos. In: VI SIMPÓSIO BRASILEIRO DE TECNOLOGIA DE ARGAMASSAS. I INTERNATIONAL SYMPOSIUM ON MORTARS TECNOLOGY, Florianópolis, 2005. p. 757-767.

GUIMARÃES, J. P. P. Técnicas tradicionais de construção, anomalias e técnicas de intervenção em fachadas e coberturas de edifícios antigos. 2009. $192 \mathrm{f}$. Tese (Mestrado de Engenharia Civil) - Universidade de Trás-Os-Montes e Alto Douro - UTAD, Vila Real, 2009.

JUNGINGER, M.; RESENDE, M. M.; CORDTS, R. M. Recomposição do revestimento das fachadas da Igreja Nossa Senhora da Consolação. In: II CONGRESSO INTERNACIONAL NA "RECUPERAÇÃO, MANUTENÇÃO E RESTAURAÇÃO DE EDIFÍCIOS. 2006, Rio de Janeiro. p. 110.

LEVY, S. M.; HELENE. P. R. L. Metodologia utilizada na restauração das fachadas do Mercado Municipal de São Paulo. In: III SIMPÓSIO BRASILEIRO DE TECNOLOGIA DAS ARGAMASSAS, 1999, Vitória - ES. Anais...PPGEC/ANTAC.1999. 633-644.

MAGALHÃES, A. C. Patologia de rebocos antigos. LNEC, Cadernos de Edifícios, $\mathrm{n}^{\circ}$ 2. 2002. P. 1-15. Disponível em: $<$ mestradoreabilitacao.fa.utl.pt/disciplinas/jbastos/Rveiga5ACristia n.pdf> Acesso: julho de 2013.

MELO JÚNIOR, C. M. Influência da chuva dirigida e dos detalhes arquitetônicos na durabilidade de revestimentos de fachada. 2010. 204 f. Dissertação (Mestrado em Engenharia Civil) - Escola de Engenharia Civil, Universidade Federal de Goiás, Goiânia, 2010. 
MELO JÚNIOR, C. M.; SHIRAKAWA, M.; TANAKA, H.; CARASEK, $H$. Influência de elementos da fachada no crescimento de microrganismos em revestimentos: estudo de caso em Goiânia In: IX SIMPÓSIO BRASILEIRO DE TECNOLOGIA DAS ARGAMASSAS, Belo Horizonte, 2011.

NASCIMENTO, G. B do. Caracterização e utilização de pó de pedra em revestimentos para restauração de edificações históricas em estilo art déco. 2008. $189 \mathrm{f}$. Dissertação (Mestrado em Construção Civil) - Escola de Engenharia, Universidade Federal de Minas Gerais, Belo Horizonte, 2008.

RIBEIRO, F. A. Especificação de juntas de movimentação em revestimentos cerâmicos de fachadas de edifícios: levantamento do estado da arte. 2006. 175 f. Dissertação (Mestrado em Engenharia Civil) - Departamento de Engenharia de Construção Civil e Urbana, Escola Politécnica da Universidade de São Paulo, São Paulo, 2006.

RILEM. TC -127 - MS Tests for masonry materials and structures. Materials and Structures. RILE M. Paris. Vol.30. p.323-328. 1998

SCHELOTTO, S. Uma abordagem do art déco no Uruguai. In: I SEMINÁRIO INTERNACIONAL: ART DÉCO NA AMÉRICA LATINA, 1997, Rio de Janeiro. Anais... Rio de Janeiro: Solar Grandjean de Montigny, PUC/RJ, 1997. 236 p, p. 45-53. ISBN 85-86505-01-3.

SILVA, C. A.; MANCINI, C. R. Patrimônio cultural art déco de Goiânia: caminhos de identidade local. In: Ministério da Educação. Secretaria de Educação Profissional e Tecnológica. Cadernos Temáticos, Brasília, 2008. v. 18, p. 25-33.

TELES, C. D. M. Inspeção de fachadas históricas: levantamento de materiais e danos de argamassas de revestimento. 2010. 321 f. Tese (Doutorado em Arquitetura) - Escola de Engenharia de São Carlos, Universidade de São Paulo, São Carlos, 2010.

TINOCO, J. E. L. Mapa de danos: recomendações básicas. Centro de Estudos Avançados da Conservação Integrada.Textos para Discussão v.43 - Série 2: Gestão de Restauro, Olinda, 23 p, 2009. ISSN: 1980-8267.

TORGAL, F. P.; JALALI, S. Algumas considerações sobre as argamassas de reabilitação. Materiais de Construção, Número 35, p. 35-39. 2010.

UNES, W. Identidade art déco de Goiânia. Goiânia: Instituto Casa Brasil de Cultura, 2008. 198 p.

VEIGA, M. R.; AGUIAR, J.; SILVA, A. S.; CARVALHO, F. Conservação e renovação de revestimentos de paredes de edifícios antigos. Coleção Conservação e Reabilitação de Edifícios. Edição 2004. Lisboa: LNEC - Laboratório Nacional de Engenharia Civil, 2004. 126 p.
VEIGA, R.; TAVARES, M.; MAGALHÃES, A. C. Restauro da fachada em marmorite de cal do Laboratório Nacional de Engenharia Civil, em Lisboa. Materiais, métodos e resultados. In: VII SEMINÁRIO BRASILEIRO DE TECNOLOGIA DAS ARGAMASSAS, 2007, Recife. Anais... ANTAC, 2007.

VELOSA, A. L. Argamassas de cal com pozolanas para revestimento de paredes antigas. Tese (doutorado), Universidade de Aveiro, 2006, Portugal.

VILLEGAS, R. Metodologia para la evaluacion y estudio previo detratamientos. In: Metodología de diagnóstico y evaluación de tratamiento para la conservación de los edificios históricos, Ed. R.Villegas Sánchez, E. Sebastián Pardo, Instituto Andaluz del Património Histórico, Sevilla, España, 2003, 194-205. 